\title{
The evolution of value with filgrastim in oncology
}

\author{
Paul Cornes*,1 \& Andriy Krendyukov**,2 \\ ${ }^{1}$ Comparative Outcomes Group, Bristol, UK \\ ${ }^{2}$ Medical Affairs, Hexal AG, Holzkirchen, Germany \\ *Author for correspondence: paul.cornes@yahoo.co.uk \\ **Author for correspondence: Tel.: +49 1728295 231; akrendyukov@gmx.de
}

The recombinant G-CSF filgrastim was first approved in 1991, and its value has been evolving ever since. Initial health technology assessments suggested low value due to high drug cost and no evidence for significant gain in overall survival. However, more recent meta-analyses of placebo-controlled randomized trial data show falling costs due to biosimilar competition and absolute overall survival gains of $3.2 \%$ (95\% Cl: 2.1-4.2\%) from filgrastim support of cytotoxic chemotherapy. The launch of biosimilar alternatives merits a re-evaluation of decisions by health technology assessments and explains the first inclusion of filgrastim in the WHO Essential Drug List for cancer $>20$ years after its original approval in 1991, thus demonstrating the power of biosimilar medicines in transforming healthcare.

First draft submitted: 5 October 2018; Accepted for publication: 1 February 2019; Published online: 5 March 2019

Keywords: biosimilar $\bullet$ cost-effectiveness $\bullet$ filgrastim $\bullet$ G-CSF $\bullet$ granulocyte colony-stimulating factor $\bullet$ value

The value of drugs evolves over time as new evidence for risks and benefits emerge and the price of a drug changes. The G-CSF filgrastim was first approved in 1991 and its value has been evolving ever since. Filgrastim is indicated for the amelioration of neutropenia in patients receiving cytotoxic chemotherapy [1-4], and since 2015, has been included on the WHO Model List of Essential Medicines: a list of minimum medicine needs for a basic healthcare system that includes the most efficacious, safe and cost-effective medicines for priority conditions [5].

Neutropenia is a commonly reported adverse event associated with cytotoxic chemotherapy, defined as a neutrophil count of $<0.5 \times 10^{9} / 1$. The duration of neutropenia determines the risk of infection, with the shorter the period of neutropenia, the lower the risk. Signs of infection in patients with neutropenia include fever and febrile neutropenia (FN). FN is defined as an oral body temperature of $\geq 38.3^{\circ} \mathrm{C}$ or two consecutive readings of $>38.0^{\circ} \mathrm{C}$ for $2 \mathrm{~h}$ in a patient with an absolute neutrophil count (ANC) $<0.5 \times 10^{9} / 1_{[4]}$. The risk of FN increases sharply as the duration of neutropenia increases [6], and to keep the risk of $\mathrm{FN}<10 \%$, the duration of neutropenia should be shortened to $<2$ days. Each year in the USA, 60,000 cancer patients are hospitalized because their low neutrophil count led to a serious infection and one in 14 of these patients dies [7]. The administration of G-CSF treatment in cancer patients depends on several factors such as type of chemotherapy regimen, comorbidities, performance status, patient age and complicating factors such as renal or hepatic dysfunction $[4,8,9]$. There is also a cost implication since estimates suggest that each patient with neutropenic fever costs almost US $\$ 28,000$ to treat [10]. A recent study showed that among 3314 breast cancer patients undergoing chemotherapy, 14\% experienced FN that required hospitalization for a mean of 4 days, at a mean cost of US $\$ 20,462$ [11]. Neutropenia also means that anticancer chemotherapy treatment may be delayed and doses are reduced if infection occurs or the patient does not recover their blood counts in time for the next treatment cycle [7,12-14]. Once chemotherapy dose delays and dose reductions reach $15 \%$, cancer cure rates fall [13]; this was reported in half of breast cancer patients prior to the introduction of G-CSF treatment to prevent neutropenia [14]. Thus, prevention is better than cure. WHO recommendations on essential medicines for cancer recognize the need for improved control of infection and improved cancer control [15], supporting the use of filgrastim in patients receiving myelosuppressive chemotherapy.

Future Medicine 


\section{Economic evaluation of filgrastim}

We performed a search with the term 'filgrastim' through the Evidence Search Portal of the UK National Institute for Health and Care Excellence (NICE) [16]. This search, on 28 August 2018, revealed 25 systematic reviews and 55 economic evaluations of filgrastim, up to the NICE Key-Topic Report 15 on biosimilar medicines for drug optimization that was updated in February 2018 [17]. These were read to find evidence for either the clinical value or the economic value of filgrastim during chemotherapy. Key papers have been summarized in Table 1.

Some early economic evaluations suggested low value due to high drug cost and no evidence for significant gain in overall survival (OS) $[22,39]$. However, this may be due to the types of patients included in these studies. For example, one study included elderly patients with aggressive non-Hodgkin's lymphoma; survival benefits may be less likely in this cohort, compared with less frail patients with less aggressive disease [39]. As a consequence of the high cost of a biologic drug and the low benefits, the cost-effectiveness of G-CSF was considered to be very poor. One study estimated its impact at more than 5 million Canadian Dollars (almost 4 million Euros) for each Quality Adjusted Life Year (QALY) gained [33,34].

The first NICE evidence with data to suggest any clinically and statistically significant survival benefit was published in 2013, more than 20 years after the first approval of filgrastim in 1991 [36,40]. This 2013 meta-analysis of placebo-controlled randomized trial data showed absolute OS gains of 3.2\% (95\% CI: 2.1-4.2\%) from filgrastim support of cytotoxic chemotherapy [36] and decreased costs due to biosimilar competition. This systematic review and meta-analysis of 61 randomized controlled trials evaluated the impact of filgrastim on chemotherapy dose intensity and cancer survival [36]. The risk reduction (RR) with G-CSF support for all-cause mortality was 0.93 (95\% CI: 0.90-0.96; $p<0.001)$. A greater RR was observed in studies with a longer follow-up ( $p=0.02$ ), where treatment was for curative intent $(R R=0.91 ; p<0.001)$, where survival was the primary outcome $(R R=0.91$; $\mathrm{p}<0.001)$ and where dose-dense chemotherapy was used [36].

The 3.2\% absolute increase in OS is particularly of note when it is considered that patients with early-stage node-negative breast cancer are treated with adjuvant chemotherapy for a $2.3 \%$ absolute survival benefit [41]. There are two probable explanations as to why filgrastim could impact on improved survival. The first is that G-CSF can improve control of infection by reducing the risk of FN, hospitalization and death during chemotherapy. The second could be that G-CSF can also meet the need for improved cancer control by allowing more chemotherapy to be given on time and without the need for dose reductions, making it more effective. We suggest that the delay of two decades to discover this survival benefit is probably explained by the lack of published data with long-term outcomes from the earlier era of research.

It is this long delay that probably explains why G-CSF was not included in the WHO Model List of Essential Medicines until 2015, 24 years after its first approval [5]. WHO reports that, "Only those medicines should be selected for which sound and adequate data on efficacy and safety are available from clinical studies, and for which evidence of performance in general use in a variety of medical settings has been obtained" [42]. Inclusion in an essential drug list mandates that G-CSF is available to all citizens, either free or for an affordable price [1]. However, since filgrastim is a recombinant biologic drug costing between US $\$ 42,000$ and US $\$ 50,000$ (USA 2012 pricing) for a typical patient having one cycle of chemotherapy, this has implications for affordability in many regions $[43,44]$.

The value of a treatment, in terms of cost-effectiveness, is determined by both its clinical effect and its financial cost. While more than two decades were needed to report the general impact of G-CSF on OS to the satisfaction of WHO, this period also spanned a change in the cost of treatment. Surveys of drug costs over time suggest that branded medicines under patent protection show pharmaceutical price inflation at rates above the general consumer price inflation [45]. This cost inflation is later checked by patent expiry and the advent of competition from other manufacturers. For traditional medicines, competition has been from 'generic' medicines [46]. The $2010 \mathrm{WHO}$ report, 'More Health for the Money', cited underuse of generics and higher than necessary prices for medicines as leading causes of inefficiency in global healthcare [46]. Reasons for this inefficiency included lower perceived efficacy and safety of generic medicines, and historical prescribing patterns. The report provided clear guidance on how to address inefficiency, including improving prescribing guidance, information, training and practice; requiring, offering or permitting incentives for generic substitution, and purchasing based on assessment of costs and benefits of alternatives [47].

The structural complexity of biologic medicines, such as G-CSF, means that generic versions are insufficient to ensure a similar quality, safety and efficacy as the original patented 'reference drug' [48]. Instead the economic role 
Table 1. Timeline of key economic studies of filgrastim prophylaxis during cancer chemotherapy.

\begin{tabular}{|c|c|c|c|}
\hline Year of publication & Country of origin & Value assessment of filgrastim & Refs. \\
\hline 1991 & USA & $\begin{array}{l}\text { Clinical value recognized. First RCT reports filgrastim reduces FN during cancer chemotherapy for small } \\
\text { cell lung cancer }\end{array}$ & [18] \\
\hline 1991 & USA/Europe & Filgrastim first approved USA and Europe & [19] \\
\hline 1996 & Italy & $\begin{array}{l}\text { Prophylactic filgrastim clinically effective but not cost-effective in the Italian hospital setting. The ICER } \\
\text { assumes no tumor control or OS advantage from filgrastim }\end{array}$ & [20] \\
\hline 2000 & Multinational & $\begin{array}{l}\text { Filgrastim cost-effectiveness decreased by identifying low-risk FN patients who do not require hospital } \\
\text { admission and so save costs using the Multinational Association for Supportive Care in Cancer Risk Index }\end{array}$ & [21] \\
\hline 2004 & The Netherlands & $\begin{array}{l}\text { Prophylactic filgrastim clinically effective but not cost effective to payers for elderly patients with } \\
\text { diffuse B-cell non-Hodgkin's Lymphoma. The ICER assumes no tumor control or OS advantage }\end{array}$ & [22] \\
\hline 2004 & UK & $\begin{array}{l}\text { Prophylactic filgrastim cost saving only in patients likely to have two episodes of FN and if drug price is } \\
\text { reduced by } \geq 85 \% \text {. The ICER assumes no tumor control or OS advantage from filgrastim }\end{array}$ & [23] \\
\hline 2004 & USA & $\begin{array}{l}\text { Prophylactic filgrastim may not be cost-effective from a payers' perspective; however, it is cost-effective } \\
\text { at FN risk } \geq 18 \% \text { when indirect patient costs are included (e.g., loss of earnings) }\end{array}$ & [24] \\
\hline 2006 & The Netherlands & $\begin{array}{l}\text { Filgrastim is cost saving to payers only when } \mathrm{FN} \text { risk } \geq 84 \% \text {. The ICER assumes no tumor control or OS } \\
\text { advantage from filgrastim }\end{array}$ & [25] \\
\hline 2006 & USA & $\begin{array}{l}\text { Widespread underdosing of filgrastim saves drug costs but leads to increased FN admissions reported } \\
\text { from large US patient outcomes database. Each additional day of filgrastim prophylaxis reduced this risk } \\
\text { between } 8 \text { and } 23 \% \text {, depending on tumor type }\end{array}$ & [16] \\
\hline 2007 & Canada & Filgrastim offers no OS benefit in meta-analysis of RCTs & [26] \\
\hline 2008 & Europe & First biosimilar filgrastim approved Europe & [27] \\
\hline 2009 & Europe & Price competition promoted in Europe with five competing brands of biosimilar filgrastim approved & [27] \\
\hline 2011 & USA & $\begin{array}{l}\text { Majority of filgrastim use in multiregional population-based cohort patients shown to be outside } \\
\text { guidelines. Restricting use would increase cost-effectiveness }\end{array}$ & [28] \\
\hline 2011 & UK & $\begin{array}{l}\text { Filgrastim price discount of } 60 \% \text { could make primary prophylaxis cost-effective for UK payer thresholds } \\
\text { of } £ 30,000 \text { per QALY if OS impact of reduced chemotherapy intensity following FN is considered. At list } \\
\text { prices, only secondary prophylaxis cost-effective at UK thresholds }\end{array}$ & [29] \\
\hline 2012 & UK & $\begin{array}{l}\text { Filgrastim prophylaxis ICER estimated at } £ 1.0-4.1 \text { million per QALY - assuming no OS gains. NICE advises } \\
\text { reimbursement only as an integral part of the chemotherapy regimen or in order to maintain } \\
\text { chemotherapy dose intensity in curative patients }\end{array}$ & {$[12,30,31]$} \\
\hline 2012 & UK & $\begin{array}{l}\text { Patient access increases fivefold with budget-saving through price competition by biosimilars for } \\
\text { London NHS }\end{array}$ & \\
\hline 2012 & Canada & $\begin{array}{l}\text { Filgrastim prophylaxis ICER estimated at CAD 700,500 per QALY in diffuse B-cell non-Hodgkin's } \\
\text { Lymphoma }\end{array}$ & [33] \\
\hline 2013 & Canada & $\begin{array}{l}\text { Filgrastim prophylaxis ICER estimated at CAD 5,796,000 per QALY in diffuse B-cell non-Hodgkin's } \\
\text { Lymphoma }\end{array}$ & [34] \\
\hline 2013 & Europe & Price competition promoted in Europe with seven competing brands of biosimilar filgrastim approved & [27] \\
\hline 2013 & Sweden & $\begin{array}{l}\text { Patient access increases fivefold with budget-saving through price competition by biosimilars in } \\
\text { southern Sweden }\end{array}$ & [35] \\
\hline 2013 & USA & $\begin{array}{l}\text { Filgrastim prophylaxis for trials reporting at least } 2 \text { years of follow-up show overall mortality reduced } \\
3.2 \% \text { absolute }(95 \% \mathrm{Cl}:-2.1 \text { to }-4.2 \%) \text {. Improved OS seen across cancer types and dose and schedule } \\
\text { categories. Greater reductions in risk for all-cause mortality were observed in studies with longer } \\
\text { follow-up }\end{array}$ & [36] \\
\hline 2014 & USA & $\begin{array}{l}\text { Filgrastim prophylaxis ICER estimated at }<U S \$ 50,000 \text { per QALY using a whole life calculation in } \\
\text { non-small cell lung cancer }\end{array}$ & [37] \\
\hline 2014 & Europe & Price competition promoted in Europe with eight competing brands of biosimilar filgrastim approved & [27] \\
\hline 2015 & USA & First biosimilar filgrastim approved USA & [19] \\
\hline 2015 & Canada & First biosimilar filgrastim approved Canada & [38] \\
\hline 2015 & World & Filgrastim given WHO essential drug status for oncology & [5] \\
\hline
\end{tabular}

of generic medicines for biologics is taken by 'biosimilar' drugs [49]. As with generic medicines, competition from biosimilars drives price reductions [50,51]. 


\section{Biosimilars}

Biosimilars are defined by WHO as, "A biotherapeutic product which is similar in terms of quality, safety and efficacy to an already licensed reference biotherapeutic product" [52]. The expiry of patents for biological drugs presents opportunities for the development of biosimilars with the rationale of cost savings and consequent improved access to biological medicines [49,53-55]. Biosimilars are a key component of the biologics market which was worth US $\$ 277$ billion in sales worldwide in 2017, and are predicted to offer savings of over $€ 10$ billion from 2016 to 2020 in the European Union Five countries (EU5: France, Germany, Italy, Spain, UK) alone [56]. Cost-saving is not the sole determinant for biosimilar uptake in Europe; local guidelines and policies are influential too [56]. In the USA, geographical differences in regulatory frameworks have led to delays in the approval and clinical uptake of biosimilar oncology drugs compared with the EU [57]. Perceived safety concerns and discounting of reference filgrastim may also have had a negative impact on the rate of approval and clinical uptake of biosimilars in the USA [57,58]. In the EU, formal postapproval risk management plans, which detail measures taken in order to ensure that new biosimilar drugs are used as safely as possible, have been set up to address these concerns [59,60].

\section{Biosimilar filgrastim}

Following approval of the first biosimilar filgrastim in 2008, several biosimilar G-CSF products are now available, offering potential for increased treatment access for patients. Biosimilars of filgrastim have been approved in Canada (one filgrastim biosimilar), USA (two filgrastim biosimilars), Europe (nine filgrastim biosimilars, one withdrawn postapproval) and Japan (three filgrastim biosimilars) and clinical and pharmacoeconomic experience is thus emerging. Current ESMO and EORTC guidelines consider biosimilar filgrastim as an alternative to reference filgrastim [4,60] and the 2017 JSCO, 2016 ASCO Guideline Update and the 2018 ASCO Statement: Biosimilars in Oncology recommend either biosimilar or reference filgrastim for FN prevention [62-64].

In the EU, where postapproval experience of biosimilar G-CSF is the longest, barriers and facilitators of adoption of the five available biosimilar filgrastims have been identified [65]. For example, data from London hospitals show that switching from reference G-CSF to biosimilar G-CSF was associated with an annual saving of $£ 1$ million [32,35]. UK guidelines were also updated to reflect the improved cost-effectiveness of biosimilar G-CSF. G-CSF was recommended as first-line cancer treatment and uptake of both reference and biosimilar filgrastim increased by $104 \%[63,66]$. Data from Sweden show that in the southern healthcare region (population 1.7 million), biosimilar G-CSF was associated with net savings of $€ 2$ million and allowed a fivefold increase in daily G-CSF usage [35]. This represented a saving of around 4 to $5 \%$ of the total drug budget. It is important to note that this region previously had restrictions regarding the use of G-CSF which were reduced since the introduction of biosimilar G-CSF $[35,67]$. Cost estimates from 17 European countries suggested that total savings from switching from the reference to the biosimilar were $€ 85$ million across the region [35,67]. A cost-effectiveness study from the European G5 countries also showed that biosimilar G-CSF was the most cost-effective approach, compared with reference, regardless of the treatment regimen [68]. These data highlight the importance of biosimilars in making treatments available for reimbursement when they may otherwise be unaffordable [69]. However, in the USA, the introduction of biosimilars has yet to deliver significant cost savings, which may be achievable through changes to current legislation and policies concerning patent litigation, naming of biosimilars, and the interchangeability, formulary listing and rebate schemes of biological reference drugs and their biosimilar counterparts [58,65,70-73].

\section{Conclusion}

Value changes over time; physicians and payers need to be aware that decisions regarding the use of medicines need constant re-evaluation, especially following the launch of biosimilar alternatives. Although not yet significant in the USA, evidence from different European countries shows the cost savings and increased access to treatment permitted by use of biosimilar filgrastim, which explains the first inclusion of filgrastim in the WHO Essential Drug List for cancer more than 20 years after its original approval in 1991 [5] and demonstrates the power of biosimilar medicines in transforming healthcare. However, affordable cancer treatment is a global challenge, with 8.2 million deaths reported due to cancer worldwide in 2012 [73]. Around 65\% of cancer-related deaths are reported in developing countries and trends suggest that the incidence of cancer in the Middle East is expected to increase more than any other part of the world over the next decade [73]. Adoption of biosimilars, including biosimilar filgrastim, has the potential to improve sustainability of healthcare in oncology, which is particularly important as the incidence of cancer increases worldwide. 


\section{Future perspective}

The values of drugs are not fixed: value evolves over time as new evidence for risks and benefits emerge and the price of a drug changes. The G-CSF filgrastim was first approved in 1991 and was rejected by all initial health technology assessments as both poor clinical and economic value. Since 2015, filgrastim has been included in the WHO Model List of Essential Medicines: a list of minimum medicine needs for a basic healthcare system [5].

Value is a measure of cost and effect. Changes to either parameter should prompt a reappraisal of the value of a medicine, and hence, its reimbursement status. Filgrastim is a drug where both parameters have changed significantly over the last three decades. Cost changes, driven by biosimilar approval, clearly influenced decisions of the value of filgrastim - evidenced by the significant increase in access to the drug in all European markets with increases up to fivefold recorded. Effect changes were driven by the realization that the effect of filgrastim influenced long-term cancer cures and not just short-term outcomes, such as hospitalization for neutropenic fever. This is evidenced by the first inclusion of filgrastim in the WHO Essential Drug List for cancer, more than 20 year after its original approval in 1991.

Health technology assessments are not static documents. The appreciation of clinical benefits evolves over time with incremental research. Cost changes are driven by near universal price rises over the period of patent protection followed by reductions due to competition on patent expiry. The high acquisition cost of biologic medicines means that biosimilar versions have the potential to transform healthcare by delivering similar outcomes at a reduced price, offering two major opportunities to increase the number of patients treated and to save money from current drug budgets to reinvest into innovative treatment programmes, providing sustainability in healthcare.

\section{Executive summary}

\section{Background}

- The G-CSF filgrastim was first approved in 1991 and its value has been evolving ever since.

Economic evaluation of filgrastim

- Some early economic evaluations suggested low value of filgrastim due to high drug cost and no evidence for significant gain in overall survival (OS).

- The first UK National Institute for Health and Care Excellence (NICE) evidence with data to suggest any clinically and statistically significant survival benefit was published in 2013, more than 20 year after the first approval of filgrastim in 1991.

- It is this long delay that probably explains why G-CSF was not included in the WHO Model List of Essential Medicines until 2015; 24 years after its first approval [5].

Biosimilars

- Biosimilars are defined by the WHO as "a biotherapeutic product which is similar in terms of quality, safety and efficacy to an already licensed reference biotherapeutic product" [52].

- The expiry of patents for biological drugs presents opportunities for the development of biosimilars with the rationale of cost savings and consequent improved access to biological medicines $[49,53,55]$.

Biosimilar filgrastim

- Following approval of the first biosimilar G-CSF in 2008, several biosimilar G-CSF products are now available.

- Cost estimates from 17 European countries suggested that total savings from switching from the reference to the biosimilar were $€ 85$ million across the region $[35,67]$.

Summary

- Evidence from different European countries shows the cost savings and increased access to treatment permitted by use of biosimilar filgrastim.

- This explains the first inclusion of filgrastim in the WHO Essential Drug List for cancer more than 20 year after its original approval in 1991 [5].

- This demonstrates the power of biosimilar medicines in transforming healthcare.

\section{Author contributions}

P Cornes and A Krendyukov conceived and designed this review, developed the search strategy, completed the searches, reviewed the included studies, prepared the manuscript, edited the manuscript and read and approved the final version prior to submission. 
Financial \& competing interests disclosure

P Cornes has been employed by the UK NHS. P Cornes has received personal fees from Accord Healthcare, Amgen, Astro, Bernstein, Biogen, British Medical Journal, Medicines for Europe/European Generics Association, Mundi Pharma, European Association for Hospital Pharmacists, European Commission, European School of Oncology, European Society for Medical Oncology, Global Academy of Health Sciences, Janssen, Lilly, Merck Serono, Napp, National Cancer Society Malaysia, Pfizer/Hospira, Pharmaceutical Association of Malaysia, Roche, Sandoz, Synsana EEIG, Teva, all outside of the submitted work.

A Krendyukov is a former employee of Hexal AG. The authors have no other relevant affiliations or financial involvement with any organization or entity with a financial interest in or financial conflict with the subject matter or materials discussed in the manuscript apart from those disclosed.

\section{Open access}

This work is licensed under the Attribution-NonCommercial-NoDerivatives 4.0 Unported License. To view a copy of this license, visit http://creativecommons.org/licenses/by-nc-nd/4.0/

\section{References}

Papers of special note have been highlighted as: $\bullet$ of interest; $\bullet \bullet$ of considerable interest

1. Zarzio SmPC (2018). www.ema.europa.eu/documents/product-information/zarzio-epar-product-information_en.pdf

2. Zarxio PI (2018). www.accessdata.fda.gov/drugsatfda_docs/nda/2015/125553Orig1s000LBL.pdf

3. Crawford J, Becker PS, Armitage JO et al. Myeloid Growth Factors, Version 2.2017, NCCN clinical practice guidelines in oncology. J. Natl Compr. Canc. Netw. 15(12), 1520-1541 (2017).

4. Klastersky J, de Naurois J, Rolston K et al. Management of febrile neutropaenia: ESMO clinical practice guidelines. Ann. Oncol. 27(Suppl. 5), v111-v118 (2016).

5. WHO model lists of essential medicines. (19th Edition) (2017). www.who.int/medicines/publications/essentialmedicines/en/

- WHO model lists of essential medicines, including filgrastim.

6. Meza L. Risk of FN with lymphoma treated with standard doses CHOP chemotherapy. Proc. ASCO 21, Abs 2640 (2002).

7. Cancer Network. Bacterial infection in patients with cancer: focus on prevention (2016). www.cancernetwork.com/articles/bacterial-infection-patients-cancer-focus-prevention

8. Bennett CL, Djulbegovic B, Norris LB, Armitage JO. Colony-stimulating factors for febrile neutropenia. N. Engl. J. Med. 368(3), 1131-1139 (2013).

9. Aapro MS, Bohlius J, Cameron DA et al. 2010 update of EORTC guidelines for the use of granulocyte-colony stimulating factor to reduce the incidence of chemotherapy-induced febrile neutropenia in adult patients with lymphoproliferative disorders and solid tumours. Eur. J. Cancer 47(1), 8-32 (2011).

10. Schilling MB, Parks C, Deeter RG. Costs and outcomes associated with hospitalized cancer patients with neutropenic complications: a retrospective study. Exp. Ther. Med. 2, 859-866 (2011).

11. Kawatkar AA, Farias AJ, Chao C et al. Hospitalizations, outcomes, and management costs of febrile neutropenia in patients from a managed care population. Support. Care Cancer 25, 2787-2795 (2017).

12. NICE. Neutropenic sepsis: prevention and management of neutropenic sepsis in cancer patients (2016). www.nice.org.uk/guidance/cg151/evidence/full-guideline-188303581

13. Bonadonna G, Valagussa P, Moliterni A, Zambetti M, Brambilla C. Adjuvant cyclophosphamide, methotrexate, and fluorouracil in node-positive breast cancer: the results of 20 years of follow-up. N. Engl. J. Med. 332, 901-906 (1995).

14. Lyman GH, Dale DC, Crawford J. Incidence and predictors of low dose-intensity in adjuvant breast cancer chemotherapy: a nationwide study of community practices. J. Clin. Oncol. 21, 4524-4531 (2003).

15. Robertson J, Barr R, Shulman LN, Forte GB, Magrini N. Essential medicines for cancer: WHO recommendations and national priorities. Bull. World Health Organ. 94, 735-742 (2016).

16. Evidence search portal of the UK National Institute for Health and Care Excellence (NICE) (2017). www.evidence.nhs.uk/

17. Key therapeutic topic 15 - Biosimilars. NICE, KTT15 (2018). www.nice.org.uk/advice/ktt15

18. Crawford J, Ozer H, Stoller R et al. Reduction by granulocyte colony-stimulating factor of fever and neutropenia induced by chemotherapy in patients with small-cell lung cancer. N. Engl. J. Med. 325, 164-170 (1991).

19. FDA News Release. FDA approves first biosimilar product Zarxio (2017). https://wayback.archive-it.org/7993/20171105050630/https: //www.fda.gov/NewsEvents/Newsroom/PressAnnouncements/ucm436648.htm

20. Messori A, Trippoli S, Tendi E. G-CSF for the prophylaxis of neutropenic fever in patients with small cell lung cancer receiving myelosuppressive antineoplastic chemotherapy: meta-analysis and pharmacoeconomic evaluation. J. Clin. Pharm. Ther. 21(2), 57-63 (1996). 
21. Klastersky J, Paesmans M, Rubenstein EB et al. The multinational association for supportive care in cancer risk index: a multinational scoring system for identifying low-risk febrile neutropenic cancer patients. J. Clin. Oncol. 18(16), 3038-3051 (2000).

22. Doorduijn JK, Buijt I, van der Holt B et al. Economic evaluation of prophylactic granulocyte colony stimulating factor during chemotherapy in elderly patients with aggressive non-Hodgkin's lymphoma. Haematologica 89, 1109-1117 (2004).

23. Hackshaw A, Sweetenham J, Knight A. Are prophylactic haematopoietic growth factors of value in the management of patients with aggressive non-Hodgkin's lymphoma? Br. J. Cancer 90, 1302-1305 (2004).

24. Cosler LE, Calhoun EA, Agboola O, Lyman GH. Effects of indirect and additional direct costs on the risk threshold for prophylaxis with colony-stimulating factors in patients at risk for severe neutropenia from cancer chemotherapy. Pharmacotherapy 24, 488-494 (2004).

25. Timmer-Bonte JNH, Adang EMM, Smit HJM et al. Cost-effectiveness of adding granulocyte colony-stimulating factor to primary prophylaxis with antibiotics in small-cell lung cancer. J. Clin. Oncol. 24, 2991-2997 (2006).

26. Sung L, Nathan PC, Alibhai SM, Tomlinson GA, Beyene J. Meta-analysis: effect of prophylactic hematopoietic colony-stimulating factors on mortality and outcomes of infection. Ann. Intern. Med. 147, 400-411 (2007).

27. GaBI Online. Biosimilars approved in Europe (2017). www.gabionline.net/Biosimilars/General/Biosimilars-approved-in-Europe

28. Potosky AL, Malin JL, Kim B et al. Use of colony-stimulating factors with chemotherapy: opportunities for cost savings and improved outcomes. J. Natl Cancer Inst. 103, 979-982 (2011).

29. Whyte S, Cooper KL, Stevenson MD, Madan J, Akehurst R. Cost-effectiveness of granulocyte colony-stimulating factor prophylaxis for febrile neutropenia in breast cancer in the United Kingdom. Value Health 14, 465-474 (2011).

30. Phillips R, Hancock B, Graham J, Bromham N, Jin H, Berendse S. Prevention and management of neutropenic sepsis in patients with cancer: summary of NICE guidance. BMJ 345, e5368 (2012).

31. Neutropenic sepsis: prevention and management of neutropenic sepsis in cancer patients. Evidence review, search strategies, health economics evidence review and health economics plan. Developed for NICE by the National Collaborating Centre for Cancer (2017). www.nice.org.uk/guidance/cg151/evidence/evidence-review-pdf-188303582

32. Chan KK, Siu E, Krahn MD, Imrie K, Alibhai SM. Cost-utility analysis of primary prophylaxis versus secondary prophylaxis with granulocyte colony-stimulating factor in elderly patients with diffuse aggressive lymphoma receiving curative-intent chemotherapy. $J$. Clin. Oncol. 30, 1064-1071 (2012).

33. Lathia N, Isogai PK, De Angelis C et al. Cost-effectiveness of filgrastim and pegfilgrastim as primary prophylaxis against febrile neutropenia in lymphoma patients. J. Natl Cancer Inst. 105, 1078-1085 (2013).

34. Gascón P, Tesch H, Verpoort K et al. Clinical experience with Zarzio ${ }^{\circledR}$ in Europe: what have we learned? Support. Care Cancer 21, 2925-2932 (2013).

-. Review of 5 years of clinical experience with Sandoz biosimilar filgrastim (Zarzio $\left.{ }^{\circledR}\right)$.

35. Lyman GH, Dale DC, Culakova $\mathrm{E}$ et al. The impact of the granulocyte colony-stimulating factor on chemotherapy dose intensity and cancer survival: a systematic review and meta-analysis of randomized controlled trials. Ann. Oncol. 24, 2475-2484 (2013).

-• First evidence to suggest any clinically and statistically significant survival benefit of filgrastim.

36. Hill G, Barron R, Fust K et al. Primary vs secondary prophylaxis with pegfilgrastim for the reduction of febrile neutropenia risk in patients receiving chemotherapy for non-Hodgkin's lymphoma: cost-effectiveness analyses. J. Med. Econ. 17, 32-42 (2014).

37. GaBI Online. Subsequent entry biologics approved in Canada (2017). www.gabionline.net/Biosimilars/General/Subsequent-entry-biologics-approved-in-Canada

38. Nichols CR, Fox EP, Roth BJ et al. Incidence of neutropenic fever in patients treated with standard-dose combination chemotherapy for small-cell lung cancer and the cost impact of treatment with granulocyte colony-stimulating factor. J. Clin. Oncol. 12, 1245-1250 (1994).

39. Ornes S. Core concepts: biosimilars. Proc. Natl Acad. Sci. USA 112, 15261-15262 (2015).

40. Early Breast Cancer Trialists' Collaborative Group. Polychemotherapy for early breast cancer: an overview of the randomized trials. Lancet 352, 930-942 (1998).

41. Drug and therapeutics committees - a practical guide. Section: 3.2.1 (2017). http://apps.who.int/medicinedocs/en/d/Js4882e/5.2.html

42. Taylor DCA, Fust K, Skornicki ME et al. Economic model of granulocyte colony-stimulating factors for patients receiving chemotherapy. Am. J. Pharm. Benefits 4, 284-292 (2012).

43. Begley S. Cancer drugs, though cheaper in the developing world, remain unaffordable in poorer countries. STAT (2016). www.statnews.com/2016/06/06/cancer-drug-prices-developing-world/

44. Joanne L, Leslie F, Brixner DI. Trends in pharmaceutical expenditures: the impact on drug benefit design. Am. Health Drug Benefits 1 , 29-34 (2008).

45. Dylst P, Vulto A, Godman B, Simoens S. Generic medicines: solutions for a sustainable drug market? Appl. Health Econ. Health Policy 11, 437-443 (2013).

46. WHO. Chapter 4: more health for the money In: World Health Report 2010. (2015). www.who.int/whr/2010/10_chap04_en.pdf 
47. Schiestl M, Zabransky M, Sörgel F. Ten years of biosimilars in Europe: development and evolution of the regulatory pathways. Drug Des. Dev. Ther. 11, 1509-1515 (2017).

48. Cornes P. The economic pressures for biosimilar drug use in cancer medicine. Target. Oncol. 7(Suppl. 1), S57-S67 (2012).

- Review conducted to assess the degree to which financial constraints will drive future health spending and if legal or safety issues could impact on any trend.

49. Mulcahy AW, Predmore Z, Mattke S. The cost savings potential of biosimilar drugs in the United States (2017). www.rand.org/content/dam/rand/pubs/perspectives/PE100/PE127/RAND_PE127.pdf

50. Quintiles IMS. The impact of biosimilar competition in Europe (2017). http://ec.europa.eu/DocsRoom/documents/23102

51. GaBI Online. WHO definitions of biosimilars (2016). http:/gabionline.net/Biosimilars/General/WHO-definitions-of-biosimilars

52. Tabernero J, Vyas M, Giuliani R et al. Biosimilars: a position paper of the European Society for Medical Oncology, with particular reference to oncology prescribers. ESMO Open 1, e000142 (2016).

-. ESMO positioning paper on biosimilars, aiming to describe the issues revolving around biosimilars that are relevant to the field of oncology, especially the prescribers.

53. Advancing Biosimilar Sustainability in Europe - A Multi-Stakeholder Assessment. IQVIA Institute Report, September 4, 2018 (2018). www.iqvia.com/institute/reports/advancing-biosimilar-sustainability-in-europe

54. Bennett CL, Chen B, Hermanson T et al. Regulatory and clinical considerations for biosimilar oncology drugs. Lancet Oncol. 15(13), e594-e605 (2014).

55. Hakim A, Ross JS. Obstacles to the adoption of biosimilars for chronic diseases. JAMA 317(21), 2163-2164 (2017).

56. Risk-management plans (2018).

www.ema.europa.eu/human-regulatory/marketing-authorisation/pharmacovigilance/risk-management/risk-management-plans

57. EMA/475472/2014, Summary of the risk management plan (RMP) for Accofil (filgrastim) (2014). www.ema.europa.eu/docs/en_GB/document_library/EPAR_-_Risk-management-plan_summary/human/003956/WC500169991.pdf

58. Aapro MS, Bohlius J, Cameron DA et al. 2010 update of EORTC guidelines for the use of granulocyte-colony stimulating factor to reduce the incidence of chemotherapy-induced febrile neutropenia in adult patients with lymphoproliferative disorders and solid tumours. Eur. J. Cancer 47(1), 8-32 (2011).

59. Japan Society of Clinical Oncology. Clinical practice guidelines. Recommendations for the use of G-CSF (2017). www.jsco-cpg.jp/item/30/index.html

60. Smith TJ, Bohlke K, Lyman GH et al. Recommendations for the use of WBC growth factors: American Society of Clinical Oncology clinical practice guideline update. J. Clin. Oncol. 33(28), 3199-3212 (2015).

61. Lyman GH, Balaban E, Diaz M et al. American Society of Clinical Oncology statement: biosimilars in oncology. J. Clin. Oncol. 36(12), 1260-1265 (2018).

62. Qureshi ZP,Nagai S, Bennett CL, Biosimilar filgrastim use in the United States vs the European Union and Japan-why does it lag behind and what can be done? JAMA Oncol. doi:10.1001/jamaoncol.2018.5636 (2018) (Epub ahead of print).

63. IMS Institute for Healthcare Informatics. Delivering on the potential of biosimilar medicines: the role of functioning competitive markets (2017). www.imshealth.com/files/web/IMSH\%20Institute/Healthcare\%20Briefs/Documents/IMS_Institute_Biosimilar_Brief_March_2016.pdf

64. IMS Health. MIDAS Global Biologics database, 2012 (2017). www.imshealth.com

65. Aapro M, Cornes P, Abraham I. Comparative cost-efficiency across the European G5 countries of various regimens of filgrastim, biosimilar filgrastim, and pegfilgrastim to reduce the incidence of chemotherapy-induced febrile neutropenia. J. Oncol. Pharm. Pract. 18, 171-179 (2012).

-• Cost-efficiency analysis of the granulocyte colony-stimulating factors (G-CSF) filgrastim (reference Neupogen ${ }^{\circledR}$ and biosimilar Zarzio $^{\circledR}$ ) and pegfilgrastim (reference Neulasta ${ }^{\circledR}$ ).

66. IMS Health. Shaping the biosimilars opportunity: a global perspective on the evolving biosimilars landscape (2017). www.imshealth.com/en

67. Chen B, Yang YT, Bennett CL. Challenges to biosimilar substitution. JAMA 318(12), 1186 (2017).

68. International Agency for Research on Cancer. Latest world cancer statistics. Global cancer burden rises to 14.1 million new cases in 2012: marked increase in breast cancers must be addressed (2018). www.iarc.fr/en/media-centre/pr/2013/pdfs/pr223_E.pdf

69. Weise M, Bielsky MC, De Smet K et al. Biosimilars: what clinicians should know. Blood 120, 5111-5117 (2012).

-. Review by the Working Party on Similar Biologic Medicinal Products of the European Medicines Agency aiming to address concerns regarding biosimilars.

70. Weise M, Kurki P, Wolff-Holz E, Bielsky MC, Schneider CK. Biosimilars: the science of extrapolation. Blood 124, 3191-3196 (2014).

-. Review aiming to address the concerns regarding the use of biosimilars in extrapolated indications using examples from recently licensed biosimilars. 
71. Chen B, Yang YT, Bennett C. Friction in the path to use of biosimilar drugs. N. Engl. J. Med. 378(22), 2148 (2018).

72. Frank RG. Friction in the path to use of biosimilar drugs. N. Engl. J. Med. 378(9), 791-793 (2018).

73. Yang YT, Chen B, Bennett CL. Biosimilars-curb your enthusiasm. JAMA Oncol. 3, 1467-1468 (2017). 
